\title{
Dissecting gene expression at the blood-brain barrier
}

\author{
Melanie A. Huntley ${ }^{1+}$, Nga Bien-Ly ${ }^{2+}$, Richard Daneman ${ }^{3 *}$ and Ryan J. Watts ${ }^{2 *}$ \\ ${ }^{1}$ Department of Bioinformatics and Computational Biology, Genentech Inc., South San Francisco, CA, USA \\ 2 Department of Neuroscience, Genentech Inc., South San Francisco, CA, USA \\ ${ }^{3}$ Department of Pharmacology, University of California, San Diego, La Jolla, CA, USA
}

\section{Edited by:}

Norman Ruthven Saunders,

University of Melbourne, Australia

Reviewed by:

Joel Pachter, University of

Connecticut Health Center, USA

Stefan Liebner, Goethe University

Clinic, Germany

\section{*Correspondence:}

Richard Daneman, Department of Pharmacology, University of

California San Diego, 9500 Gilman

Drive 0636, La Jolla, 92093 CA, USA

e-mail: rdaneman@ucsd.edu;

Ryan J. Watts, Department of

Neuroscience, Genentech Inc.,

1 DNA Way, South San Francisco,

94080 CA, USA

e-mail:watts.ryan@gene.com

${ }^{\dagger}$ These authors have contributed

equally to this work.
The availability of genome-wide expression data for the blood-brain barrier is an invaluable resource that has recently enabled the discovery of several genes and pathways involved in the development and maintenance of the blood-brain barrier, particularly in rodent models. The broad distribution of published data sets represents a viable starting point for the molecular dissection of the blood-brain barrier and will further direct the discovery of novel mechanisms of blood-brain barrier formation and function. Technical advances in purifying brain endothelial cells, the key cell that forms the critical barrier, have allowed for greater specificity in gene expression comparisons with other central nervous system cell types, and more systematic characterizations of the molecular composition of the blood-brain barrier. Nevertheless, our understanding of how the blood-brain barrier changes during aging and disease is underrepresented. Blood-brain barrier data sets from a wider range of experimental paradigms and species, including invertebrates and primates, would be invaluable for investigating the function and evolution of the blood-brain barrier. Newer technologies in gene expression profiling, such as RNA-sequencing, now allow for finer resolution of transcriptomic changes, including isoform specificity and RNA-editing. As our field continues to utilize more advanced expression profiling in its ongoing efforts to elucidate the blood-brain barrier, including in disease and drug delivery, we will continue to see rapid advances in our understanding of the molecular mediators of barrier biology. We predict that the recently published data sets, combined with forthcoming genomic and proteomic blood-brain barrier data sets, will continue to fuel the molecular genetic revolution of blood-brain barrier biology.

\section{HISTORICAL PERSPECTIVE ON DATASETS}

In 1967 using exogenous peroxidase, Reese and Karnovsky demonstrated the subcellular localization of the blood-brain barrier (BBB) to be the endothelium forming the walls of vessels in the brain (Reese and Karnovsky, 1967). Two structural characteristics distinguished these endothelial cells from those in the heart and skeletal muscle: the presence of tight junctions, and the paucity of micropinocytotic vesicles. Early studies used microscopy and immunohistochemistry to visualize the presence and localization of a handful of known proteins within brain endothelial cells (BECs) (Risau et al., 1986), while in situ hybridization filled in the gaps for questions about expression patterns when antibodies were not available for specific targets. Nearly fifty years later, the underlying genes and developmental cascades that result in the unique traits of BECs are just beginning to be understood. Current critical advancements in our ability to both purify and culture BECs now allow for the study of their

Abbreviations: ABC, ATP binding cassette; BBB, blood-brain barrier; BEC, brain endothelial cell; FACS, fluorescence activated cell sorting; HBMEC, human brain microvessel endothelial cell; hCMEC/D3, human cerebral microvascular endothelial cell line; HUVEC, human umbilical vein endothelial cell; LCM, laser capture microdissection; miRNA, microRNA. molecular mechanisms at an unprecedented level of breadth and depth.

Since the seminal discovery that brain endothelial cells limit the diffusion of blood-borne molecules, the following decades of work have made it clear that the BBB is not just a physical wall but a complex regulated physiology that allows the BECs to determine the movement of ions, molecules and cells between the blood and the neural tissue. At the heart of this physiology are molecular and structural specializations of BECs that differentiate them from endothelial cells in non-neural tissue. BECs are held together by tight junctions, which form a tight paracellular barrier that polarizes the cells into distinct luminal and abluminal membrane compartments. This tight paracellular junction coupled with the extremely low levels of transcytosis creates a physical barrier to hydrophilic molecules and allows cellular transport properties to determine movement of molecules between the blood and the brain. To regulate this movement, BECs express a series of different transporters that generally fall into two categories: efflux transporters and nutrient transporters (for an in depth review of BBB transporters see Saunders et al., 2013). Briefly, efflux transporters, such as ABCB1 (also known as p-glycoprotein, or Pgp), face the luminal surface and use energy generated from the hydrolysis of ATP to pump a wide 
array of lipophilic substrates up their concentrations gradients into the blood, thus limiting the passive diffusion of hydrophobic molecules into the brain. Nutrient transporters, such as Glut-1 (glucose transporter SLC2A1), Lat-1 (amino acid transporter light chain, SLC7A5) and Mct-1 (monocarboxylate transporter, SLC16A1), facilitate the movement of specific substrates down their concentration gradients, allowing specific molecules into or out of the brain. Thus, the BBB is not solely a physical barrier but it is a series of complex regulated physiological specializations of the BECs that control the microenvironment of the brain. Furthermore, work has demonstrated that many of these specializations of the BECs are not intrinsic, but regulated by interactions with neural cells including CNS pericytes and astrocytes, and immune cells including microglia and macrophages (Hudson et al., 2005; Armulik et al., 2011). Identifying the molecular signature of BECs and how they differ from ECs in other tissues, as well as key cell-cell signaling interactions in the neurovascular unit, are questions at the forefront in understanding the physiology of the BBB.

\section{THE UTILITY OF DATASETS AS RESOURCES}

High quality gene expression data has significantly impacted the direction of investigation by allowing for a better molecular understanding of BBB development, function, and dysfunction. Well-powered gene expression studies can validate hypothesis driven queries or open previously unexplored avenues of research in unbiased directions. Models of acute BBB dysfunction, such as stroke or ischemia, aid in elucidating mechanisms of impairment for development of therapeutics or preventative treatments. An understanding of BBB-specific transporter, receptor, and ion channel expression levels could benefit drug development efforts by aiding in the design of selective compounds for those that could evade efflux pumps (Pottiez et al., 2009) or utilize receptors to enhance therapeutic uptake in brain (Yu and Watts, 2013).

The variety of questions and issues that can be addressed related to BBB development and disease have vastly improved, thanks in part to genetic engineering approaches in rodents and other species, improved cellular isolation techniques, and the availability of bioinformatics software and experts that facilitate the mining of data sets for relevant genes worthy of further investigation. The combination of "big data" sets and moleculargenetic tools is beginning to elucidate biological mechanisms in many arenas, and our understanding of BBB biology is benefiting from this revolution.

\subsection{KEY PARAMETERS FOR BBB GENOMIC STUDIES}

The cellular complexity of the BBB presents a significant obstacle in the gathering of meaningful gene expression data. Brain endothelial cells are surrounded by the mural cells-pericytes and smooth muscle cells-and are further encapsulated by a basement membrane (see Figure 1C). The ensheathment of the vessels by astrocytic endfeet, likely receiving signals from neurons and microglia, serve to further regulate brain vascular function (Abbott, 2005). Therefore, these various cell types are intimately connected and unite in maintaining the integrity of the BBB. Thus a global analysis of BBB gene expression may necessitate the co-purification and co-analysis of these important non-BEC cell types along with BECs (Shusta, 2005). Early efforts to harvest brain vasculature for genomic analysis captured a majority of the cell types associated with BECs of the neurovascular unit. These earlier protocols relied on mechanical brain dissociation to isolate microvascular components, a technique known as vascular enrichment (Triguero et al., 1990; Boado and Pardridge, 1991), which uses a series of filtrations through nylon membranes or with glass beads followed with gradient centrifugation steps (Betz et al., 1979; Yousif et al., 2007). This contrasted with laser capture microdissection (LCM) methods for single capillary fragment isolation, which allows for highly localized sampling from specific human and mouse brain sections and could be restricted to diseased regions (Ball et al., 2002; Mojsilovic-Petrovic et al., 2004). Again, both methods do not specifically yield pure populations of BECs specifically, however, they do allow for a sampling of cells associated with the neurovascular unit and generally enrich for BECs for inferences to be drawn about CNS microvasculature.

Thus, several important considerations must be taken into account when designing genomic experiments to analyze the BBB. The most important parameter is to determine the desired cells or tissues to be analyzed and the method of purification. Because the key properties of the BBB are specializations of BECs, many studies have used methods to purify ECs from brain tissue, whereas others have used crude approaches to purify vessels (endothelial cells and pericytes) or entire fragments of the neurovascular unit (see Figure 1). In addition, the vasculature of the brain contains many different segments of the vascular tree including arteries, arterioles, capillaries, post-capillary venules, venules, and veins (Dorr et al., 2007), all of which contain barrier properties but each segment may have different transport, metabolic, signaling and cell adhesion properties. Gradient centrifugation has been used to specifically isolate microvessels (capillaries and post-capillary venules), whereas purification based on markers of ECs will contain BECs from all segments of the vascular tree. Also taken into consideration should be the species from which the samples are isolated, whether human, rodent or other model organism, and whether to examine acutely purified or cultured cells. The second parameter is the method of analysis. For transcriptomic generation of EST libraries, subtractive hybridization, microarrays and RNA sequencing are all common methods to examine RNA. Different methods of RNA extraction, including whole RNA, mRNA, small RNA, and tagged-ribosome isolation can highlight specific RNAs of interest. In addition, proteomics, metabolomics, lipidomics, epigenomics, and other "omics" analysis can give an even broader overview of the molecular composition of the BBB. The third parameter is the effective comparisons used for differential gene expression analysis. Identifying all the transcripts in a given cell can be challenging to decipher, however, generating a comparison of two cells that vary only for a given function can greatly narrow down the search for important genes. In the case of the BBB, several important comparisons have been made, including comparing BECs with whole brain extracts to identify EC specific genes, as well as comparing BECs with peripheral ECs to identify BBB-specific specializations (see Table $\mathbf{1}$ for a summary of recent BBB expression profiling studies). The fourth important parameter to determine is the physiological setting in which to analyze the BBB. Much work has been done to identify 


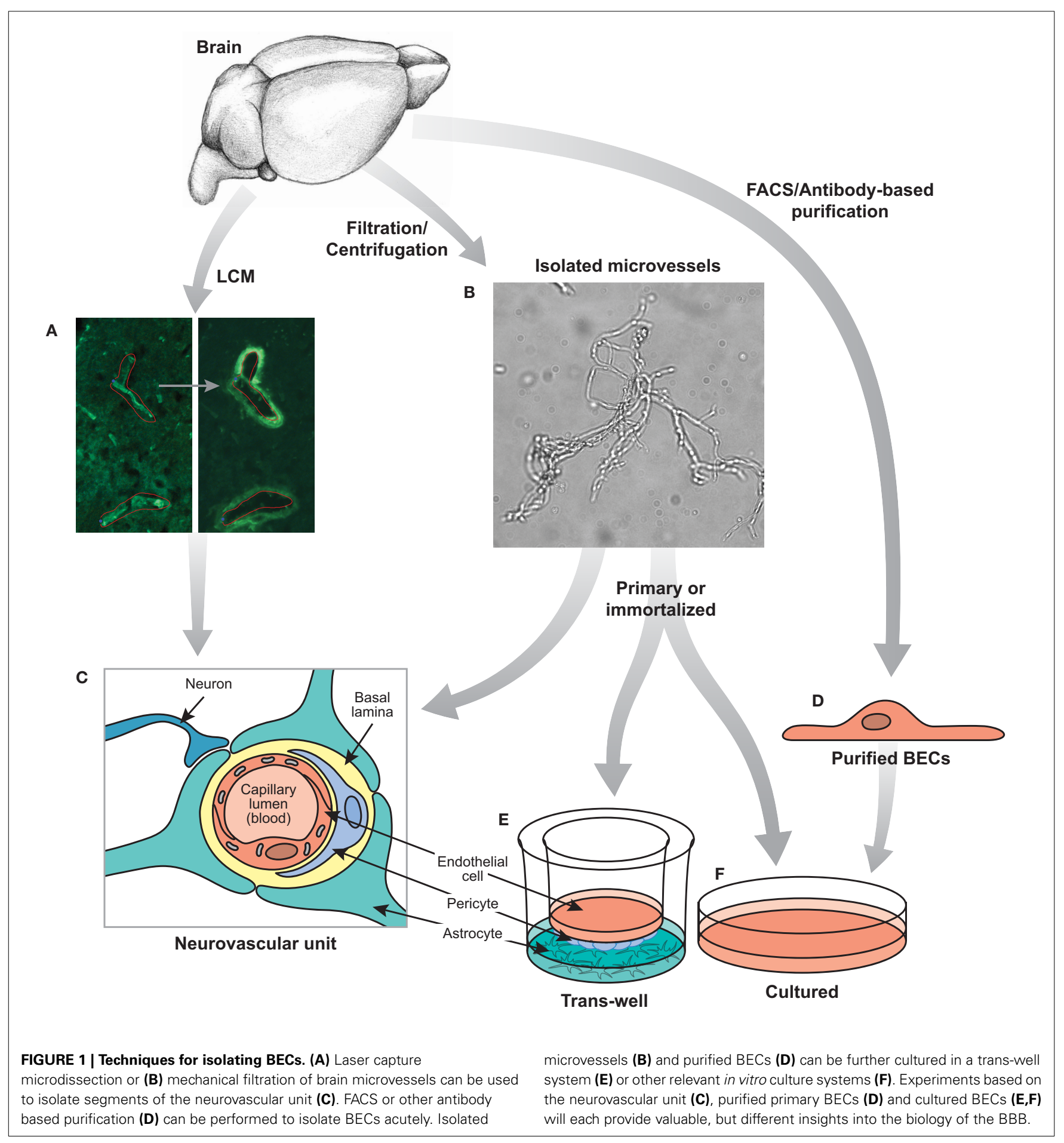

the gene expression signature of the $\mathrm{BBB}$ in a healthy adult animal, but studies have also examined the BBB during development, in different neurological disease settings, in mice with different mutations that affect BBB formation and function, or with the addition of different pharmacological agents. Each of these parameters will greatly influence the data set obtained and therefore careful consideration must be taken to ensure the best method of BEC purification and analysis.

\subsection{METHODS OF ANALYSIS}

Earlier transcriptomic approaches that yielded important initial insights on brain microvascular specific expression data included suppression subtractive hybridization and serial analysis of gene expression (SAGE) (Li et al., 2001; Shusta et al., 2002; Enerson and Drewes, 2006; Calabria and Shusta, 2008). For a detailed review on these techniques and early results, see Shusta (2005), Pottiez et al. (2009). A distinguishing aspect of the SAGE study of 
Table 1 | Recent genomewide microarray expression data sets for the BBB.

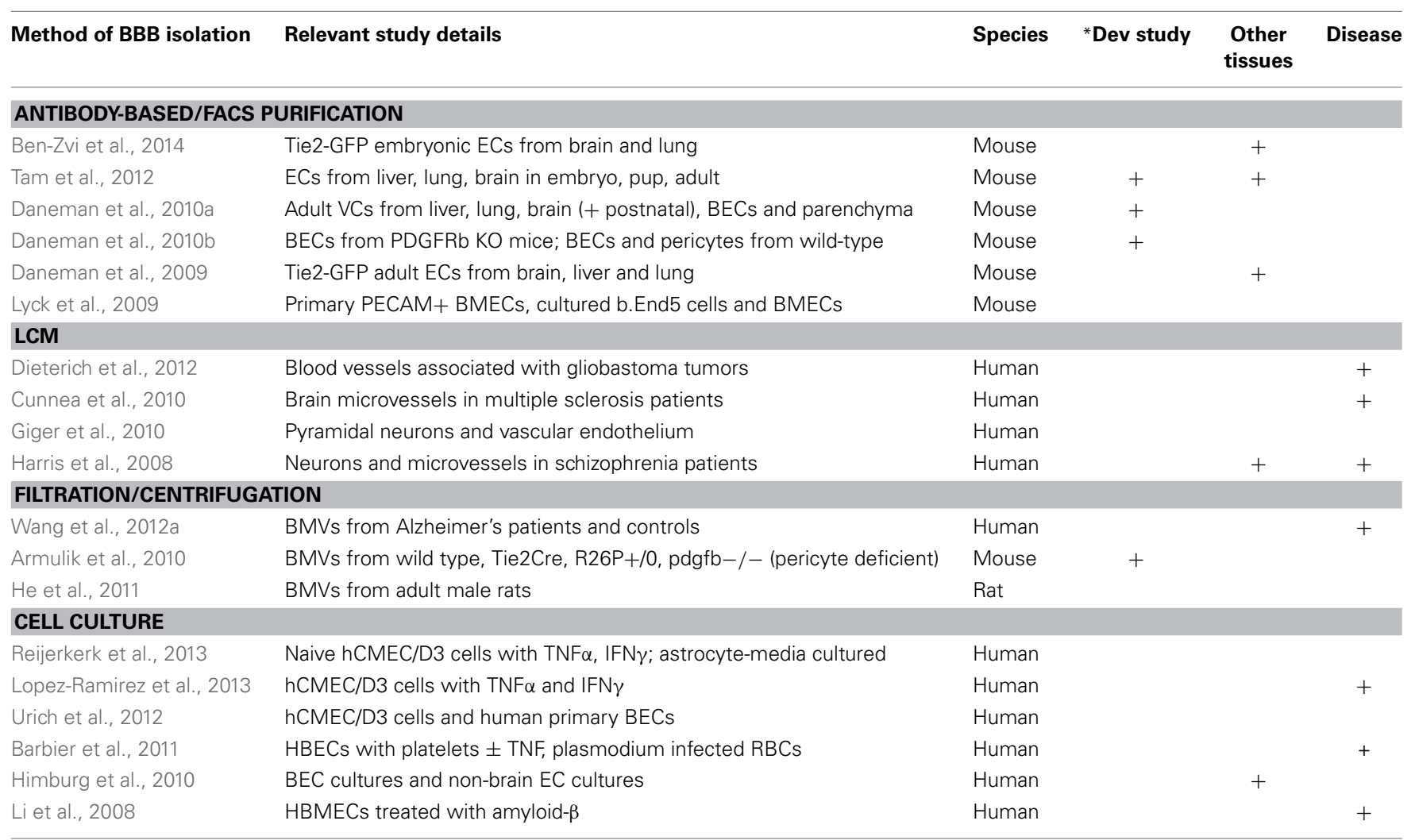

*Developmental stages. BEC, brain endothelial cell; BMEC, brain microvascular endothelial cell; BMV, brain microvessel; HBEC, human brain endothelial cell; $H B M E C$, human brain microvessel endothelial cells; $E C$, endothelial cell; $R B C$, red blood cell; VC, vascular cell.

rat brain microvessels was the comparison to rat neocortex and hippocampus tag catalogs and the resulting identification of 864 BBB enriched genes.

Today, expression microarrays offer a mature and commonly used platform to differentially compare gene expression between two samples. One of the earliest $\mathrm{BBB}$ gene expression studies using microarray established a protocol to profile human brain endothelial cells co-cultured with astrocytes under dynamic conditions with controlled intraluminal flow (Marroni et al., 2003). The authors observed that exposure to increased flow up-regulated cytoskeletal genes while also inhibiting cell cycling genes.

In the era of microarray data sets on the BBB (see Table 1), the number of genes that are queried on commercially available chips has increased several orders of magnitude, moving the field into truly high-throughput experiments and data. In addition, relatively small amounts of cells or tissue are now required for genome-wide transcriptomic approaches, thus facilitating a wide range of studies. Advancements and maturity of computational tools for this type of data analysis are now available allowing investigators to dive into these data sets and identify meaningful connections (Irizarry et al., 2003; Gentleman et al., 2004; Smyth, 2004; Falcon and Gentleman, 2007; Kauffmann et al., 2009). Online repositories, such as Gene Expression Omnibus and the European Nucleotide Archive, now allow researchers to deposit genome wide expression data sets to be queried and re-used by other groups. Indeed, many of the studies listed in Table 1 have made use of previously published expression data sets from the $\mathrm{BBB}$ as an integral part of their analyses. The importance of continuing to expand the public availability of such data sets as an ongoing resource for the community cannot be overstated.

A discussion of newer techniques, such as next generation RNA-sequencing, will follow at the conclusion of this review.

\section{EXPERIMENTAL PARADIGMS ANALYZED}

Figure 1 summarizes the most common methods for isolation and purification used in BBB genome-wide expression studies. As many recent studies have shown, in vitro models of the $\mathrm{BBB}$ do not fully recapitulate the complexity of an intact organism. The use of newer techniques such as fluorescence activated cell sorting (FACS), immunopanning, magnetic bead immunoprecipitation, as well as advances to LCM may aid in acutely harvesting specifically BECs, or an enriched population of BECs, for downstream transcriptomic and proteomic studies. Navone et al. (2013) document recent protocols for the isolation of human and mouse brain microvascular endothelial cells. However, no technique or protocol is perfect as there are subtle considerations to be aware of which may factor largely into downstream data analysis. Even careful acute isolation and genomic profiling of BECs may be susceptible to general expression changes induced by mechanical shearing of brain parenchyma and/or microvessel tissue, enzymatic digestion, temperature fluctuations, etc. Careful pair-wise 
comparisons with the proper controls undergoing similar handling are critical to minimize bias in the data.

\subsection{ACUTE ISOLATION AND PURIFICATION OF BRAIN MICROVASCULAR CELLS}

The use of antibody-based techniques to isolate rodent brain endothelial cells has been reported in several recent studies. Magnetic beads coupled to murine or rat antibodies against CD31/PECAM allow for immunoprecipitation of endothelial cells from homogenates of brain (Lyck et al., 2009) and possibly other vascular organs for direct comparisons. Likewise, antibodies against CD31 can be immobilized onto culture plates for immunopanning enrichment of brain homogenates for acute isolation of BECs (Zhou et al., 2014a) or the use of other cell surface receptors such as anti-PDGFR $\beta$ for pericytes (Daneman et al., 2010b). This approach also allows for a negative selection step against microglia or pericytes to remove these non-BEC subtypes from the overall homogenate. A third BEC-specific antibody or antigen-selection technique utilizes fluorescence-activated cell sorting which would use either a fluorophore-coupled anti-BEC cellular marker (Daneman et al., 2010b; Tam et al., 2012) or transgenic mice that harbor BEC-specific promoters to direct expression of a fluorescent protein, such as Tie2-GFP mice (Daneman et al., 2009, 2010a; Ben-Zvi et al., 2014).

Moreover, LCM has experienced many improvements including the addition of immunostaining protocols and brighter, more specific dyes for identification of brain endothelia (Macdonald et al., 2008). Recent immuno-LCM studies have described differences in gene expression of brain capillaries vs. venules, and highlighted important roles for their heterogeneity (Macdonald et al., 2010). Increased antibody availability for other neurovascular unit cell types have also enabled cross comparison of gene expression as well as validation of cell type specificity of the data sets generated by mass spectrometry (Murugesan et al., 2011). Advances in equipment such as microscopes with automated stages, higher quality cameras, and sophisticated software have enabled more consistent tissue sampling and higher throughput.

\subsection{IN VITRO BBB MODELS}

Immortalized cell lines derived from rodent or human brain endothelial cells have been frequently used as a model system for gene expression studies despite their questionable physiological relevance. Cultured cells, especially those that can be passaged indefinitely, represent a key model system that allows for a high level of cellular homogeneity, consistency, and experimental reproducibility. Key components of the neurovascular unit can be reconstituted in vitro by growing BECs on filter inserts that sit above pericytes and/or astrocytes, allowing signaling mechanisms between these cell types to remain largely intact. Conversely, in vitro models may still lack the complex interactions between these cell types and the endogenous extracellular matrix, as well as surrounding neurons and microglia that exist in vivo. Complicated disease processes that are also in play in vivo are likely difficult to fully model in a transwell culture system and suffer from numerous drawbacks (Hawkins and Egleton, 2008; Pottiez et al., 2009). In other words, the neurovascular unit is essentially an organ system with numerous cellular interactions that make it virtually impossible to replicate outside of the organism. However, these culture paradigms also do enable investigators to determine what individual cell types can do in the absence of other cells, or with defined cellular interactions. For instance, culturing BECs alone can give an idea of which BBB properties are independent of signaling interactions within the neurovascular niche. Furthermore, by adding feeder layers of individual cells, such as astrocytes or pericytes, or signaling molecules or pharmacological agents, in vitro models can aid in determining how these factors directly influence BEC gene expression.

Primary BEC culture models obtained from bovine or rodent acutely isolated brain microvessels present another system for directed studies on BBB maintenance and function. Early efforts relied on isolation and enrichment of brain capillaries from rats followed by enzymatic digestion of the basement membrane to allow migration of endothelial cells for growth on an artificial substrate (Bowman et al., 1981). Bovine models have allowed for several benefits including greater amounts of starting material obtained from one animal, less variability between cultures from the same starting material, and importantly, retention of endothelial characteristics after serial passaging (Goetz et al., 1985).

The establishment of human cerebral microvessel cultures also yielded early, important insights into BBB function (Vinters et al., 1987). These culture systems were improved upon as tighter barriers were introduced with co-culture models containing astrocytes and by introducing intraluminal flow (Marroni et al., 2003). Human brain microvessel endothelial cells (HBMEC) have also been treated with amyloid- $\beta$ to determine their gene expression changes using a cDNA array and identified a putative protective role for STC1 (Li et al., 2008).

\subsection{COMPARISONS OF ACUTE VS. CULTURED BBB MODELS}

Whether in vitro BBB models were derived from immortalized cell lines or acutely isolated from mouse or human brains, extensive efforts to characterize their gene expression signature have repeatedly revealed their limited approximation of in vivo complexity. Comparisons of BBB gene expression profiles from acutely isolated mouse brain endothelial cells vs. a period of brief culturing, or compared against a commonly used mouse brain endothelioma line (bEND5) revealed evidence of dedifferentiation of BEC qualities (i.e., reduced levels of tight junction proteins and amino acid transporters) induced by primary culture or immortalization (Lyck et al., 2009). A similar study which used suppression subtractive hybridization revealed that some transport-related brain endothelial genes were subsequently downregulated after BECs spent several days in culture compared to freshly isolated rat brain microvessels (Calabria and Shusta, 2008). The same study compared cultures containing puromycin (which decreases numbers of contaminating pericytes) for BEC expression and also the effect of hydrocortisone on cultures. More recently, transcriptome data from immortalized human BEC line hCMEC/D3 and primary human BEC (Urich et al., 2012) were compared with published data on acutely isolated mouse BECs (Daneman et al., 2010a) to highlight differences in levels of endothelial marker expression. 
The authors found that although the human cells demonstrated expression of tight junction proteins, transporters and receptors, their levels were dramatically reduced compared to acutely isolated mouse BECs (Urich et al., 2012).

Nevertheless, using in vitro BBB models may yield some important initial insights into BEC response to external stimuli or stress. hCMEC/D3 cells have been recently profiled for their transcriptional response to $\mathrm{TNF} \alpha$ and IFN $\gamma$ and gene expression signatures identified span from factors involved in antigen presentation, cellular adhesion, cytokine-induced signaling pathways, to reduced transporter expression (Lopez-Ramirez et al., 2013). These data were compared to similar historical data sets that included TNF $\alpha$-treated human umbilical vein (HUVEC) and primary human cerebral endothelial cell cells (Franzen et al., 2003).

\subsection{MODELS OF BBB DEVELOPMENT}

$\mathrm{Wnt} / \beta$-catenin signaling has been implicated in driving CNS specific angiogenesis and regulating BBB formation and maintenance (Liebner et al., 2008; Stenman et al., 2008; Daneman et al., 2009; Wang et al., 2012b; Zhou et al., 2014b). Using microarray expression profiling comparing BECs with ECs from non-neural tissue, Daneman and colleagues identified that genes downstream of $\mathrm{Wnt} / \beta$-catenin signaling were greatly enriched in endothelial cells of the brain but not liver or lung (Daneman et al., 2009, 2010a). Performing sophisticated genetic and functional experiments, the authors demonstrate that $\mathrm{Wnt} / \beta$-catenin signaling is required to drive CNS-specific angiogenesis but not angiogenesis in other tissues. To identify if this CNS-specific angiogeneic program also induced BBB-specific gene expression in the endothelial cells, the authors utilized gene expression profiling of purified mouse brain endothelial cells cultured with and without Wnt ligands to find that Wnt induced the expression of BBB-specific nutrient transporters in the endothelial cells, and further showed that loss of Wnt signaling in vivo led to loss of Glut-1 expression in endothelial cells. More recently, Zhou et al. (2014b) demonstrated nearly identical canonical Wnt signaling mechanisms of development and maintenance between both the blood-brain and blood-retinal barriers.

The characterization of molecular cues and signaling pathways that guide both physiological and pathophysiological CNS angiogenesis may also stand to benefit greatly from expanded efforts at expression profiling of BECs within various parts of the neurovascular unit. Common guidance molecules that regulate both nerve and vascular remodeling such as Sema/Plex/Nrp, Slit/Robo, Netrin/Unc5, VEGF, and its tyrosine kinase receptors Flt-1 and Flk-1, have been extensively studied, however, the role of the canonical axon guidance molecules in CNS angiogenesis is less studied (Tam and Watts, 2010). Transcriptomics may also enable future studies on understanding the role of TGFb or EphB receptors and ligands in determining arteriovenous identity within the brain vasculature (Adams and Alitalo, 2007; Engelhardt and Liebner, 2014).

In addition to the involvement of Wnt signaling in $\mathrm{BBB}$ angiogenesis and barriergenesis, the role of growth factors and kinases beyond VEGF and Notch have also been further characterized. Mice deficient in PDGF-B lack microvascular pericytes and succumb to lethal microaneurisms during development due to incomplete brain vascularization (Lindahl et al., 1997). More recent studies on the importance of pericytes in barriergenesis and maintenance reported that significantly reduced pericyte coverage in $\operatorname{PDGFR} \beta$ null fetal mice translated into increased permeability (Daneman et al., 2010b). Transcriptome signatures of BECs isolated from null mice were compared to wild type mice, which revealed increases in Angpt2, a Tie2 ligand involved in vascular permeability of peripheral endothelial cells but no downregulation of $\mathrm{BBB}$-enriched genes. Thus pericytes may regulate the $\mathrm{BBB}$ by inhibiting the expression of genes that normally make endothelial cells leaky. In addition, the expression profile of pericytes acutely isolated from wild type mice was also generated, further providing a valuable data set for BBB neurovascular unit transcript comparisons (Daneman et al., 2010b).

For an in depth review on recent studies of developmental barriergenesis and repair, see Obermeier et al. (2013), Siegenthaler et al. (2013), Engelhardt and Liebner (2014).

\subsection{EVOLUTIONARY STUDIES OF THE BBB}

Two distinct cellular mechanisms of BECs appear to be evolutionarily conserved across all vertebrates and some invertebrates, including the fruit fly model organism, Drosophila melanogaster. These conserved traits include the tight junctions that prevent paracellular diffusion, and ATP binding cassette (ABC) transporters that efflux molecules back into the vascular luminal space. The Drosophila genome encodes proteins which are nearly identical in sequence to those that comprise vertebrate tight junctions (Wu and Beitel, 2004; Banerjee et al., 2006), and whose disruption leads to defects in humoral-CNS barrier function (Schwabe et al., 2005; Stork et al., 2008). Further, Mayer et al. (2009) established that the fly protein Mdr65 functions as an $\mathrm{ABC}$ transporter in the Drosophila hemolymph-brain barrier.

Validation of gene expression data in other species with a simplistic BBB may expedite the search for candidate genes that warrant further study in rodents or human tissue. For example, we recently profiled the rodent $\mathrm{BBB}$ at three developmental stages, used zebrafish to confirm the necessity of candidate genes in regulating angiogenesis, and followed with subsequent analysis of genetic interactions of two death receptors, DR6 and TROY, by returning to mice to confirm a role for these genes in rodent $\mathrm{BBB}$ development (Tam et al., 2012). As such, conserved pathways can be discovered in one species and further characterized in more tractable models. In fact, fruit fly, grasshopper, and zebrafish are gaining popularity as models for high throughput screening of BBB drug permeability studies (Nielsen et al., 2011; Geldenhuys et al., 2012) It is this underlying premise of evolutionary conservation which provides confidence that understanding the $\mathrm{BBB}$ in rodent and other model organisms will be relevant to the human BBB.

Primate studies, on the other hand, can illuminate more recent evolutionary innovations relevant to the human $\mathrm{BBB}$. Gene expression differences between neurons and BECs from human postmortem tissue isolated by LCM were compared with published data sets on chimpanzees and rhesus macaques for analysis of rates of transcriptome evolution in neuronal vs. endothelial cell types (Giger et al., 2010). The authors found that transcriptomes 
of neurons and endothelial cells evolve at different rates within brain tissue. This finding adds complexity to the challenge of translating $\mathrm{BBB}$ results from other species, even closely related species, into human models.

\subsection{HUMAN BBB DATA SETS FOCUSED ON AGING, DISEASE, AND DYSFUNCTION}

During normal aging, the blood brain barrier experiences functional changes, which can result in impairment and dysfunction of the barrier. Marques et al. (2013) provide a review of these changes in both the $\mathrm{BBB}$ and blood-CSF barriers. In the $\mathrm{BBB}$, these changes include loosening of tight junctions, increases in pinocytotic vesicles, and decreases in mitochondrial density within ECs. The authors highlight the similarity between normal aging, and CNS disease related changes of the BBB. Since human BBB data from patients typically comes from those with obviously progressed symptoms, it is a challenge to determine if the changes in BBB function are causal or consequential to disease progression. Improvements in animal models of CNS diseases with BBB impairment may help answer such questions.

Nevertheless, several human studies in diverse disease paradigms have sought to understand vascular expression differences between healthy control and disease tissue. Microvascular endothelial cells from postmortem schizophrenia brains were isolated by LCM and their functional profile was compared to neurons and control tissue in a study by Harris et al. (2008). They found that the cerebral microvasculature of schizophrenic patients displayed a hypo-inflammatory status and this observation was reproducible on a separate microarray platform. This gene set could be useful in comparison studies with similar rodent models of cognitive dysfunction or with human BBB gene sets from patients with other cognitive or behavioral impairments. Likewise, the use of LCM to isolate vessels from glioblastoma multiforme brain tissue followed by microarray analysis and $\mathrm{qPCR}$ validation identified uniquely upregulated genes specific to tumor tissue and absent in nonmalignant human brain (Pen et al., 2007). Interestingly, a similar study from another group did not identify the same upregulated genes and describe a different expression signature (Dieterich et al., 2012). Another recent study also used LCM to query genes expressed at the BBB from multiple sclerosis lesions isolated from postmortem tissue (Cunnea et al., 2010).

Brain endothelial cell transcriptomes from human neurodegenerative diseases have been distinctly underrepresented. However, there is no shortage of studies reporting genome-wide data sets from Alzheimers disease brain or sub-regions such as hippocampus (Blalock et al., 2004; Dunckley et al., 2006; Webster et al., 2009; Blalock et al., 2011). To the best of our knowledge, the only published data set generated thus far representing the $\mathrm{BBB}$ in human neurodegeneration is from a study where brain microvessels from control and Alzheimers disease tissue were transcriptionally profiled to identify abnormal gene expression or differentially expressed genes (Wang et al., 2012a). A comparison of this data set with brain microvasculature gene expression data derived from mouse models of Alzheimer's disease may serve as a useful tool for model validation.

\subsection{RODENT BBB DATA SETS IN MODELS OF NEURODEGENERATION AND DISEASE}

Transgenic mouse models of Alzheimers disease have been instrumental to the study of amyloid- $\beta$ accumulation and its role in neuronal impairment and cognitive dysfunction. Transcriptome analysis of whole brain, specific subregions, various disease time points, and in multiple Alzheimer's disease transgenic models or after experimental treatments has been performed (Dickey et al., 2003; Reddy et al., 2004; Lazarov et al., 2005; Gatta et al., 2014). Genomic studies specifically using mouse brain vasculature from Alzheimer's disease models, on the other hand, remain sparse. The most recent study used a proteomics approach from homozygous Tg-SwDI mice which harbor three familial, autosomal dominant mutations on APP, and demonstrate sustained increases in vascular amyloid- $\beta$ accumulation over time (Searcy et al., 2014). The authors compared brain microvessel fractions from 3- and 9-month old wild type and transgenic mice for aging-related effects on the mouse vascular proteome as well as amyloid- $\beta$-induced effects. They found distinct sets of proteins changed in young and old wild type and transgenic mice, indicating a differential effect of age on the cerebrovasculature.

An experimental mouse model of multiple sclerosis, experimental autoimmune encephalomyelitis, is characterized primarily by dysfunction of the BBB. Functional studies have produced insights into the role of particular genes, such as the chemokine CXCL12, and the permeability of the BBB in experimental autoimmune encephalomyelitis (McCandless et al., 2006, 2009). However, to our knowledge, there does not yet exist a genome wide expression data set derived from the BBB in this important model of multiple sclerosis.

Metabolic diseases, with obesity a leading factor, may also have a multitude of effects on the BBB and as a result, CNS function. A recent study on diet-induced obesity using a mouse model profiled the proteomic changes in brain vasculature after 2 months of high fat diet chow administered starting at 2 months of age (Ouyang et al., 2014). The samples were compared directly with mice maintained on normal chow and the authors found 47 downregulated and 2 upregulated proteins, indicating that in general, diet-induced obesity suppressed metabolic activity in brain microvessels (Ouyang et al., 2014).

Rodent models exist for other neurological diseases associated with BBB dysfunction, including stroke, epilepsy, ALS, and neuromyelitis optica. However, to date, there is a void of genome wide expression data on brain endothelial cells from these important models. Future data sets derived from these models will be invaluable in bridging the knowledge gap between our understanding of healthy BBB maintenance and BBB dysfunction in disease.

Another genomic data set that is publicly available and could be used as a valuable cross-reference tool describes the transcriptional changes in four rat brain tissues/regions including striatum, and parietal cortex, choroid plexus, and the meninges and its associated vasculature (Bowyer et al., 2013). This study also included a time course analysis to profile the effects of amphetamines or environment-induced hypothermia on choroid plexus and the meninges. 


\section{SUMMARY OF INSIGHTS FROM BBB GENOMIC STUDIES 4.1. OVERVIEW}

Genomic studies on the BBB have provided a number of large data sets identifying genes that are expressed by BECs, enriched in BECs compared to peripheral ECs, and also genes that change levels during development or disease context. The challenge now is to sort through these vast data sets and untangle which of these large numbers of genes are functionally important for the formation and function of the $\mathrm{BBB}$, and which can be targeted to either modulate the $\mathrm{BBB}$ during neurological disease or to use as carriers for drug delivery across the BBB. Two positive outcomes have arisen from these data sets: (1) many of these analyses that use completely different methodologies have identified the same BBB genes, and (2) virtually all of the data sets have verified the expression and BBB-enrichment of commonly studied genes important for BBB function including tight junctions (claudin 5, occludin, Zo-1, Zo-2), efflux transport (P-glycoprotein, and ABCG2, also known as Bcrp), nutrient transport (Glut-1, Mct-1, Lat-1) and others (basigin, carbonic anhydrase 4 ). The strong reproducibility and ability to verify positive hits suggests that these data sets will indeed provide an extremely strong blueprint for identification of novel genes important for BBB function.

\subsection{SIGNALING REGULATORS}

Several important discoveries have already been generated from these data sets. For instance, the identification that a cluster of Wnt/ $\beta$-catenin signaling components and downstream targets (Fzd6, Lef1, Axin2, Dixdc1, Apcdd1, Troy) are greatly enriched in BECs compared to peripheral ECs led to the hypothesis that Wnt may be an important regulator of the BBB. As discussed above, several groups have verified and identified that $\mathrm{Wnt} / \beta$-catenin signaling is required for driving CNS-specific angiogenesis, BBB induction and maintenance (Liebner et al., 2008; Stenman et al., 2008; Daneman et al., 2009; Wang et al., 2012b). Beyond the morphogens Wnt and Shh, and the canonical VEGF and Notch signaling pathways, a further understanding of other growth factors and kinases involved in angiogenesis have also been possible from expression data. Moreover, gene cluster/pathway analysis can provide an important method to sift through large data sets to find groups of genes that are functionally important. Other clusters associated with BBB-enrichment are genes involved in retinoid signaling, amino acid metabolism and glycolysis, suggesting that these may be important for unique function of BECs.

\subsection{MOLECULAR COMPONENTS OF THE BARRIER}

Many groups have used these data sets to identify individual genes that are important for BBB function. Lipolysis stimulated receptor (Lsr) was identified as enriched in BECs compared to peripheral ECs (Daneman et al., 2010a), has recently been shown to recruit tricellulin/Marveld2 to tricellular tight junctions for the formation of epithelial barriers (Masuda et al., 2011), and could potentially have a similar function at the BBB. Like Lsr, Marveld2 was identified as enriched at the $\mathrm{BBB}$ along with other tight junction components such as Jam4, Mpp7 and Cgnl1 (Daneman et al., 2010a), suggesting that these may also be important for formation of BBB tight junctions. Interestingly, the genomic data sets have not added much clarity as to which claudins may be important for BBB function. While it is well established that claudin 5 is most critical in transmembrane adhesion for BEC tight junctions (Nitta et al., 2003), various studies have also implicated claudin 1, claudin 3, claudin 12 and other claudins as expressed by BECs (Liebner et al., 2000; Nitta et al., 2003; Wolburg et al., 2003; Krause et al., 2008; Pfeiffer et al., 2011). Several different genomic data sets have essentially come to different conclusions as to which claudins are expressed by BECs. Array studies on purified mouse BECs have suggested that in addition to claudin 5 , claudin 12 is the other claudin expressed by BECs (Daneman et al., 2010a; Tam et al., 2012), while cultured cells have identified claudin 3 as a component of BEC tight junctions (Liebner et al., 2008), and proteomics on human passaged endothelial cells have identified a wider array of claudins present at these junctions (Ohtsuki et al., 2013). These differences may result from species differences, differences in acutely isolated vs. cultured cells, or different sensitivities of analyses, and further work needs to be done to determine which are the important molecules.

\subsection{TRANSPORTERS AND DRUG DELIVERY TARGETS}

The genomic data sets have also identified a huge number of molecular transporters highly expressed and enriched in BECs compared to peripheral ECs. In addition to widely studied BBB transporters (Glut-1, Lat-1, Mct-1), a number of other transporters have been identified and include molecules that transport neurotransmitters (Slc6a6, Slc6a17), thiamine (Slc19a3), nucleotides (Slc25a33), carnitine (Slc25a20), zinc (Slc20a1, Slc39a10) and riboflavin (Slc52a2/Gpr172b) (Lyck et al., 2009; Daneman et al., 2010a). Determining the expression and function of this wide array of transporters may be important to understand the nutrient requirements of the CNS. A recent study by Ben-Zvi et al. (2014) selectively profiled E15.5 embryos for transcripts enriched at the BBB vs. lung endothelium and identified Mfsd2a, a lipid transporter required for docosahexaenoic acid transport (Nguyen et al., 2014), further confirming its high expression levels. Analyzing the expression of transporters and signaling components may also identify novel molecules to target for drug delivery to the CNS. The most commonly utilized target for BBB-specific receptor-mediated drug delivery to the CNS is transferrin receptor, which has been identified as highly expressed and enriched in BECs by a number of data sets (Li et al., 2001; Enerson and Drewes, 2006), suggesting that other targets may also be identified. Interestingly, a peptide targeting Lrp1 has been shown to target molecules across the BBB, however, several genomic studies identified Lrp8, and not Lrp1, as highly expressed and enriched in BECs (Daneman et al., 2010a; Tam et al., 2012). For a detailed review on the expression of transporters at the blood-brain and blood-CSF interfaces in the developing and adult brain, see Saunders et al. (2013).

\section{EMERGING FRONTIERS 5.1. PROTEOMICS}

One major criticism of transcriptomic approaches is that transcript abundance does not necessarily correlate with protein levels and actual functional activity. To that end, proteomic approaches 
may nicely complement gene expression studies. For a detailed review of proteomic studies which describe how various cell culturing conditions can significantly affect protein profiles and also how protein expression is explored using in vivo models of ischemia, stroke, inflammation, and disease, see Pottiez et al. (2009). Additionally, global genomic approaches are often followed with validation by qPCR assays and new developments in microfluidic devices have enabled higher throughput of expression validation studies from the same profiled samples, as well as the inclusion of a multitude of other samples, with or without experimental treatments, or from disease models and patients.

However, a major consideration of current proteomics BBB data is again the purity of the cell population being queried. Many BBB proteomics data are largely obtained from brain microvessel preparations consisting of additional pericytic or astrocytic connections that are in direct contact with BECs which are known to contain concentrated levels of cell-type specific receptors or channel proteins (see Table 2). Detection of known proteins such as those expressed on astrocytic endfeet (Chun et al., 2011), can be easily separated, however, lesser known hits may not be readily segregated by cell type or fall within a general category. A recent effort to profile one specific branch of CNS vasculature, the arteries comprising the Circle of Willis, generated an extensive data set of 6630 proteins, of which a third are specific to the cerebral arterial landscape (Badhwar et al., 2014). Interestingly, because isolation of the sampled tissue was via manual dissection and performed under light microscopy, whole units of arterial mediators such as neuronal regulators of vasoactivity, presumably from nerve terminals, as well as regulators of smooth muscle relaxation and contractility were identified. The cerebral artery-specific proteome was compared to the mouse microvessel proteome which revealed that intracortical microvessels had more BBB-unique protein numbers and that Circle of Willis arteries were less developed and specialized compared to microvessels (Badhwar et al., 2014). Additional studies have also compared human brain microvessel proteomic signatures with mouse (Uchida et al., 2011).

Investigators have tried to circumvent these issues by coupling gene expression with proteomics in analyses of human brain vasculature isolated from resected glioma or epileptic lesions (Dauchy et al., 2008; Shawahna et al., 2011). Furthermore, a proteomics report of young and aged primate brain microvasculature provides a highly quantitative snapshot of membrane proteins expressed at the BBB at two stages of development (Ito et al., 2011). The data were compared to mouse BBB proteomic findings, which revealed significant differences. These comparisons may provide a cautionary note when translating findings between rodents and primates, likely impacting nervous system drug development studies focused on using mouse BBB models to understand transporter and receptor expression levels (Kamiie et al., 2008; Ito et al., 2011).

Overall, proteomic studies have been incredibly useful in identifying novel molecules. In particular, proteomic analysis of lipid rafts isolated from cultured cells has identified leukocyte adhesion molecules, ninjurin, Alcam, and Mcam, that are critical for trafficking of specific subsets of immune cells into the CNS during neuroinflammatory disease (Wosik et al., 2007; Cayrol et al.,

Table 2 | Recent proteomics data sets for the BBB.

\begin{tabular}{|c|c|c|c|c|c|}
\hline Method of BBB isolation & Relevant study details & Species & $\begin{array}{l}{ }^{*} \text { Dev } \\
\text { study }\end{array}$ & $\begin{array}{l}\text { Other } \\
\text { tissues }\end{array}$ & Disease \\
\hline \multicolumn{6}{|l|}{ LCM } \\
\hline Lu et al., 2008 & Microvessels from CD31+ immunostained brain & Mouse & & & \\
\hline Haqqani et al., 2005 & In vivo ischemia & Rat & & & + \\
\hline \multicolumn{6}{|c|}{ FILTRATION/CENTRIFUGATION } \\
\hline Badhwar et al., 2014 & Surgical dissection of circle of Willis brain artery & Mouse & & & \\
\hline Ouyang et al., 2014 & Mouse model of diet-induced obesity and control & Mouse & & & + \\
\hline Searcy et al., 2014 & Effect of aging on BMVs from wild type and Tg-SwDI mice & Mouse & + & & + \\
\hline Agarwal et al., 2012 & BMVs from wild type and P-gp/Bcrp knockout & Mouse & & & \\
\hline Chun et al., 2011 & Membrane fraction of BMVs & Mouse & & & \\
\hline Ito et al., 2011 & BMVs from neonate, child, and adult & Cyno monkey & + & & \\
\hline Shawahna et al., 2011 & BMVs from epilepsy patients and glioma patients & Human & & & + \\
\hline Uchida et al., 2011 & Human and mouse BMVs & Human and mouse & & & \\
\hline Kamiie et al., 2008 & Membrane fraction of microvessels from brain, liver and kidney & Mouse & & + & \\
\hline \multicolumn{6}{|l|}{ CELL CULTURE } \\
\hline Ohtsuki et al., 2013 & hCMEC/D3 compared to isolated human BMVs and HUVECs & Human & & + & \\
\hline Pottiez et al., 2010 & BCECs co-cultured with glial cells & Cow & & & \\
\hline Pottiez et al., 2009 & BMECs cultured with and without astrocytes & Cow & & & \\
\hline Lu et al., 2007 & MECs from brain and heart & Rat & & + & \\
\hline Haqqani et al., 2007 & Immortalized BECs and in vitro ischemia & Rat & & & + \\
\hline
\end{tabular}

*Developmental stages. BCEC, brain capillary endothelial cell; BEC, brain endothelial cell; BMEC, brain microvessel endothelial cell; BMV, brain microvessel; hCMEC/D3, human cerebral microvascular endothelial cell line; HUVEC, human umbilical vein endothelial cell. 
2008; Ifergan et al., 2011). This suggests that the cultured cells may provide a model for "activated" endothelial cells and thus a good model to study their interaction with immune cells that might occur during neurological disease. In addition to these established functions of the BBB, these data sets may identify novel and unknown genes that could point to novel functions of the BBB. Although a daunting task, examining the function and regulation of each of these genes and pathways should provide incredible insight into how our brain interacts with the humoral space.

\subsection{MicroRNA}

MicroRNA (miRNA) arrays have also been used to identify and understand their role in regulating gene expression levels at the BBB in disease. Using hCMEC/D3 cells treated with TNF $\alpha$ and IFN $\gamma$, Reijerkerk et al. (2013) set out to profile the microRNAs that modulate BBB function under inflammatory conditions. With a panel of miRNAs identified to have differential expression induced by inflammatory mediators that also displayed opposing changes after barrier induction in the cell line, the authors further examined their expression in brain capillaries isolated via filtration from resected multiple sclerosis patient lesions. These samples showed decreased expression of miR-125a-5p (Reijerkerk et al., 2013). In another study using a miRNA array of 318 candidates, mouse brain endothelioma line bEND3 cells were profiled for altered miRNA expression in response to lupus serum or C5a (Eadon et al., 2014). Studies similar to these, for example evaluating freshly isolated BECs for miRNA expression at different developmental times or in diverse disease models, will further expand our knowledge of how gene expression is regulated at the $\mathrm{BBB}$.

\subsection{RNA-SEQUENCING}

RNA sequencing is a high-throughput, quantitative transcriptomic approach that is rapidly gaining popularity (Lister et al., 2008; Mortazavi et al., 2008; Nagalakshmi et al., 2008; Wilhelm et al., 2008), especially as more genome annotations are completed for more and more species. RNA-seq data also allows for the relatively unbiased discovery of alternative splicing within transcripts. Where the bulk of our transcriptome based knowledge has been driven by methods that illuminate overall gene expression (including microarray and SAGE), we have until recently, been lacking much of the important resolution afforded by identification of alternative splicing events. Many of the genes encoding proteins that form tight junctions and $\mathrm{ABC}$ transporters, for example, have distinct isoforms resulting from alternative splicing events. Future additional RNA-seq experiments with $\mathrm{BBB}$ data will provide a foundation for our future understanding of the relevance of such splicing behavior with respect to barrier development, maintenance, and dysfunction.

The high-throughput sequencing of transcriptomes afforded by RNA-seq technologies also facilitates the study of RNA editing. The process of RNA editing, which is most prevalent in the brain, is a post-transcriptional modification that can influence splicing patterns, coding sequence, and a host of other gene regulatory functions. Indeed, some of the best-studied RNA-editing events that result in altered protein isoforms occur within neuronal glutamate receptors. Future RNA-seq experiments will be needed to explore the role of RNA-editing within brain endothelial cells specifically.

Currently, BBB RNA-seq data is limited to a single dataset from mouse (at the time this review was submitted), which is already providing an extensive view of the expression landscape of not only BECs, but also neurons, astrocytes, oligodendrocytes, and microglia (Zhang et al., 2014). The authors of this study primarily used FACs and immunopanning methods to purify specific cell types, thus minimizing cross contamination and enabling greater quantitative comparisons. In addition, this valuable dataset has been made available to the public via a searchable website which includes differential splicing data (Zhang et al., 2014).

To supplement the paucity of RNA-seq data derived from the $\mathrm{BBB}$, a recent developmental study using RNA sequencing to understand brain-CSF barrier formation assembled a comprehensive list of transcripts differentially enriched between E15 embryo and P42 adult rat lateral ventricle choroid plexus (Liddelow et al., 2013). This served as a quantitative approach to update a prior microarray study (Liddelow et al., 2012). The authors performed immunohistochemistry to demonstrate embryonic and choroid plexus epithelium-specific expression of genes they found enriched via RNA-seq (Liddelow et al., 2013).

The RNA-seq approach has also been used to profile expression signatures of single cells. In a study where cultured cortical neuron transcriptomes of single cells were compared to individual layer 5 pyramidal neurons in situ, the authors found that gene expression levels correlated better amongst single cultured neurons compared to the single neurons sampled in situ (Qiu et al., 2012). This in vivo heterogeneity may also apply to cells of the BBB and thus future gene expression studies sampling single BECs or capillary fragments from distinct disease regions or developmental stages of individual vascular branches may reveal further complexity in expression of specific transporters or receptors.

\subsection{FINAL REMARKS}

Advancements in techniques for the isolation and purification of BECs and in the technologies to study the resulting transcriptomes and proteomes make for an exciting and promising future for the BBB research community. Transcriptome wide data for human diseases associated with BBB dysfunction, and corresponding animal models are under-represented in the current selection of BBB data sets. Future studies may also identify sexual dimorphisms to the $\mathrm{BBB}$, how the $\mathrm{BBB}$ changes in response to neuronal activity, during normal aging, as well as following intake of different drugs. Furthermore, understanding heterogeneity of the BBB between different segments of the vascular tree as well as between different regions of the brain may be important in our understanding of how the BBB interacts with neural cells to regulate brain function and behavior. Filling these gaps with data that are as close to the in vivo setting as possible, and utilizing techniques such as FACS or LCM, will be of great benefit. Finally, the continued commitment to share newly generated data sets in publicly accessible repositories will undoubtedly propel forward our understanding of BBB biology at an unprecedented pace. 


\section{ACKNOWLEDGMENTS}

We sincerely thank Allison Bruce for her graphics, Sabya Biswas for LCM imaging, and all the investigators who have shared their data sets publicly for the benefit of the research community.

\section{REFERENCES}

Abbott, N. J. (2005). Dynamics of CNS barriers: evolution, differentiation, and modulation. Cell Mol. Neurobiol. 25, 5-23. doi: 10.1007/s10571-004-1374-y

Adams, R. H., and Alitalo, K. (2007). Molecular regulation of angiogenesis and lymphangiogenesis. Nat. Rev. Mol. Cell Biol. 8, 464-478. doi: 10.1038/nrm2183

Agarwal, S., Uchida, Y., Mittapalli, R. K., Sane, R., Terasaki, T., and Elmquist, W. F. (2012). Quantitative proteomics of transporter expression in brain capillary endothelial cells isolated from Pglycoprotein (P-gp), breast cancer resistance protein (Bcrp), and P-gp/Bcrp knockout mice. Drug Metab. Dispos. 40, 1164-1169. doi: 10.1124/dmd.112.044719

Armulik, A., Genove, G., and Betsholtz, C. (2011). Pericytes: developmental, physiological, and pathological perspectives, problems, and promises. Dev. Cell. 21, 193-215. doi: 10.1016/j.devcel.2011.07.001

Armulik, A., Genove, G., Mae, M., Nisancioglu, M. H., Wallgard, E., Niaudet, C., et al. (2010). Pericytes regulate the blood-brain barrier. Nature 468, 557-561. doi: $10.1038 /$ nature09522

Badhwar, A., Stanimirovic, D. B., Hamel, E., and Haqqani, A. S. (2014). The proteome of mouse cerebral arteries. J. Cereb. Blood Flow. Metab. 34, 1033-1046. doi: $10.1038 /$ jcbfm.2014.52

Ball, H. J., McParland, B., Driussi, C., and Hunt, N. H. (2002). Isolating vessels from the mouse brain for gene expression analysis using laser capture microdissection. Brain Res. Brain Res. Protoc. 9, 206-213. doi: 10.1016/S1385299X(02)00147-2

Banerjee, S., Sousa, A. D., and Bhat, M. A. (2006). Organization and function of septate junctions, an evolutionary perspective. Cell Biochem. Biophys. 46, 65-77. doi: 10.1385/CBB:46:1:65

Barbier, M., Faille, D., Loriod, B., Textoris, J., Camus, C., Puthier, D., et al. (2011). Platelets alter gene expression profile in human brain endothelial cells in an in vitro model of cerebral malaria. PLoS One 6:e19651. doi: 10.1371/journal.pone.0019651

Ben-Zvi, A., Lacoste, B., Kur, E., Andreone, B. J., Mayshar, Y., Yan, H., et al. (2014). Mfsd2a is critical for the formation and function of the blood-brain barrier. Nature 509, 507-511. doi: 10.1038/nature13324

Betz, A. L., Csejtey, J., and Goldstein, G. W. (1979). Hexose transport and phosphorylation by capillaries isolated from rat brain. Am. J. Physiol. 236, c96-c102.

Blalock, E. M., Buechel, H. M., Popovic, J., Geddes, J. W., and Landfield, P. W. (2011). Microarray analyses of laser-captured hippocampus reveal distinct gray and white matter signatures associated with incipient Alzheimer's disease. J. Chem. Neuroanat. 42, 118-126. doi: 10.1016/j.jchemneu.2011. 06.007

Blalock, E. M., Geddes, J. W., Chen, K. C., Porter, N. M., Markesbery, W. R., and Landfield, P. W. (2004). Incipient Alzheimer's disease: microarray correlation analyses reveal major transcriptional and tumor suppressor responses. Proc. Natl. Acad. Sci. U.S.A. 101, 2173-2178. doi: 10.1073/pnas.0308512100

Boado, R. J., and Pardridge, M. M. (1991). A one-step procedure for isolation of poly (A)+ mRNA from isolated brain capillaries and endothelial cells in culture. J. Neurochem. 57, 2136-2139. doi: 10.1111/j.1471-4159.1991.tb06433.x

Bowman, P. D., Betz, A. L., Ar, D., Wolinsky, J. S., Penney, J. B., Shivers, R. R., et al. (1981). Primary culture of capillary endothelium from rat brain. In Vitro 17, 353-362. doi: 10.1007/BF02618147

Bowyer, J. F., Patterson, T. A., Saini, U. T., Hanig, J. P., Thomas, M., Camacho, L., et al. (2013). Comparison of the global gene expression of choroid plexus and meninges and associated vasculature under control conditions and after pronounced hyperthermia or amphetamine toxicity. BMC Genom. 14, 147-2164. doi: 10.1186/1471-2164-14-147

Calabria, A. R., and Shusta, E. V. (2008). A genomic comparison of in vivo and in vitro brain microvascular endothelial cells. J. Cereb. Blood Flow Metab. 28, 135-148. doi: 10.1038/sj.jcbfm.9600518

Cayrol, R., Wosik, K., Berard, J. L., Dodelet-Devillers, A., Ifergan, I., Kebir, H., et al. (2008). Activated leukocyte cell adhesion molecule promotes leukocyte trafficking into the central nervous system. Nat. Immunol. 9, 137-145. doi: 10.1038/ni1551
Chun, H. B., Scott, M., Niessen, S., Hoover, H., Baird, A., Yates, J., et al. (2011). The proteome of mouse brain microvessel membranes and basal lamina. J. Cereb. Blood Flow Metab. 31, 2267-2281. doi: 10.1038/jcbfm.2011.104

Cunnea, P., McMahon, J., O’Connell, E., Mashayekhi, K., Fitzgerald, U., and McQuaid, S. (2010). Gene expression analysis of the microvascular compartment in multiple sclerosis using laser microdissected blood vessels. Acta Neuropathol. 119, 601-615. doi: 10.1007/s00401-009-0618-9

Daneman, R., Agalliu, D., Zhou, L., Kuhnert, F., Kuo, C. J., and Barres, B. A. (2009). Wnt/beta-catenin signaling is required for CNS, but not non-CNS, angiogenesis. Proc. Natl. Acad. Sci. U.S. A. 106, 641-646. doi: 10.1073/pnas.0805165106

Daneman, R., Zhou, L., Agalliu, D., Cahoy, J. D., Kaushal, A., and Barres, B. A. (2010a). The mouse blood-brain barrier transcriptome: a new resource for understanding the development and function of brain endothelial cells. PLoS ONE 5:e13741. doi: 10.1371/journal.pone.0013741

Daneman, R., Zhou, L., Kebede, A. A., and Barres, B. A. (2010b). Pericytes are required for blood-brain barrier integrity during embryogenesis. Nature 468, 562-566. doi: 10.1038/nature09513

Dauchy, S., Dutheil, F., Weaver, R. J., Chassoux, F., Daumas-Duport, C., Couraud, P. O., et al. (2008). ABC transporters, cytochromes P450 and their main transcription factors: expression at the human blood-brain barrier. J. Neurochem. 107, 1518-1528. doi: 10.1111/j.1471-4159.2008.05720.x

Dickey, C. A., Loring, J. F., Montgomery, J., Gordon, M. N., Eastman, P. S., and Morgan, D. (2003). Selectively reduced expression of synaptic plasticity-related genes in amyloid precursor protein + presenilin-1 transgenic mice. J. Neurosci. 23, 5219-5226.

Dieterich, L. C., Mellberg, S., Langenkamp, E., Zhang, L., Zieba, A., Salomaki, H., et al. (2012). Transcriptional profiling of human glioblastoma vessels indicates a key role of VEGF-A and TGFbeta2 in vascular abnormalization. J. Pathol. 228, 378-390. doi: 10.1002/path.4072

Dorr, A., Sled, J. G., and Kabani, N. (2007). Three-dimensional cerebral vasculature of the CBA mouse brain: a magnetic resonance imaging and micro computed tomography study. Neuroimage 35, 1409-1423. doi: 10.1016/j.neuroimage.2006.12.040

Dunckley, T., Beach, T. G., Ramsey, K. E., Grover, A., Mastroeni, D. Walker, D. G., et al. (2006). Gene expression correlates of neurofibrillary tangles in Alzheimer's disease. Neurobiol. Aging. 27, 1359-1371. doi: 10.1016/j.neurobiolaging.2005.08.013

Eadon, M. T., Jacob, A., Cunningham, P. N., Quigg, R. J., Garcia, J. G., and Alexander, J. J. (2014). Transcriptional profiling reveals that C5a alters miRNA in brain endothelial cells. Immunology. 143, 363-373. doi: 10.1111/imm.12314

Enerson, B. E., and Drewes, L. R. (2006). The rat blood-brain barrier transcriptome. J. Cereb. Blood Flow Metab. 26, 959-973. doi: 10.1038/sj.jcbfm.9600249

Engelhardt, B., and Liebner, S. (2014). Novel insights into the development and maintenance of the blood-brain barrier. Cell Tissue Res. 355, 687-699. doi: 10.1007/s00441-014-1811-2

Falcon, S., and Gentleman, R. (2007). Using GOstats to test gene lists for GO term association. Bioinformatics 23, 257-258. doi: 10.1093/bioinformatics/btl567

Franzen, B., Duvefelt, K., Jonsson, C., Engelhardt, B., Ottervald, J., Wickman, M., et al. (2003). Gene and protein expression profiling of human cerebral endothelial cells activated with tumor necrosis factor-alpha. Brain Res. Mol. Brain Res. 115, 130-146. doi: 10.1016/S0169-328X(03)00185-2

Gatta, V., D'Aurora, M., Granzotto, A., Stuppia, L., and Sensi, S. L. (2014). Early and sustained altered expression of aging-related genes in young $3 \times \mathrm{Tg}-\mathrm{AD}$ mice. Cell Death Dis. 5:e1054. doi: 10.1038/cddis.2014.11

Geldenhuys, W. J., Allen, D. D., and Bloomquist, J. R. (2012). Novel models for assessing blood-brain barrier drug permeation. Expert Opin. Drug Metab Toxicol. 8, 647-653. doi: 10.1517/17425255.2012.677433

Gentleman, R. C., Carey, V. J., Bates, D. M., Bolstad, B., Dettling, M., Dudoit, S., et al. (2004). Bioconductor: open software development for computational biology and bioinformatics. Genome Biol. 5:R80. doi: 10.1186/gb-2004-5-10-r80

Giger, T., Khaitovich, P., Somel, M., Lorenc, A., Lizano, E., Harris, L. W., et al. (2010). Evolution of neuronal and endothelial transcriptomes in primates. Genome Biol. Evol. 2, 284-292. doi: 10.1093/gbe/evq018

Goetz, I. E., Warren, J., Estrada, C., Roberts, E., and Krause, D. N. (1985). Longterm serial cultivation of arterial and capillary endothelium from adult bovine brain. In Vitro Cell Dev. Biol. 21, 172-180. doi: 10.1007/BF02621355

Harris, L. W., Wayland, M., Lan, M., Ryan, M., Giger, T., Lockstone, H. et al. (2008). The cerebral microvasculature in schizophrenia: a laser capture microdissection study. PLoS ONE 3:e3964. doi: 10.1371/journal.pone.0003964 
Haqqani, A. S., Kelly, J., Baumann, E., Haseloff, R. F., Blasig, I. E., and Stanimirovic, D. B. (2007). Protein markers of ischemic insult in brain endothelial cells identified using 2D gel electrophoresis and ICAT-based quantitative proteomics. $J$. Proteome Res. 6, 226-239. doi: 10.1021/pr0603811

Haqqani, A. S., Nesic, M., Preston, E., Baumann, E., Kelly, J., and Stanimirovic, D. (2005). Characterization of vascular protein expression patterns in cerebral ischemia/reperfusion using laser capture microdissection and ICAT-nanoLCMS/MS. FASEB J. 19, 1809-1821. doi: 10.1096/fj.05-3793com

Hawkins, B. T., and Egleton, R. D. (2008). Pathophysiology of the blood-brain barrier: animal models and methods. Curr. Top Dev. Biol. 80, 277-309. doi: 10.1016/S0070-2153(07)80007-X

He, Z., Cui, L., Patterson, T. A., and Paule, M. G. (2011). Defining the phosphodiesterase superfamily members in rat brain microvessels. ACS Chem. Neurosci. 2, 600-607. doi: $10.1021 / \mathrm{cn} 2000487$

Himburg, H. A., Muramoto, G. G., Daher, P., Meadows, S. K., Russell, J. L., Doan, P., et al. (2010). Pleiotrophin regulates the expansion and regeneration of hematopoietic stem cells. Nat. Med. 16, 475-482. doi: 10.1038/nm.2119

Hudson, L. C., Bragg, D. C., Tompkins, M. B., and Meeker, R. B. (2005). Astrocytes and microglia differentially regulate trafficking of lymphocyte subsets across brain endothelial cells. Brain Res. 1058, 148-160. doi: 10.1016/j.brainres.2005.07.071

Ifergan, I., Kebir, H., Terouz, S., Alvarez, J. I., Lecuyer, M. A., Gendron, S., et al. (2011). Role of Ninjurin-1 in the migration of myeloid cells to central nervous system inflammatory lesions. Ann. Neurol. 70, 751-763. doi: 10.1002/ana. 22519

Irizarry, R. A., Hobbs, B., Collin, F., Beazer-Barclay, Y. D., Antonellis, K. J., Scherf, U., et al. (2003). Exploration, normalization, and summaries of high density oligonucleotide array probe level data. Biostatistics 4, 249-264. doi: 10.1093/biostatistics/4.2.249

Ito, K., Uchida, Y., Ohtsuki, S., Aizawa, S., Kawakami, H., Katsukura, Y., et al. (2011). Quantitative membrane protein expression at the blood-brain barrier of adult and younger cynomolgus monkeys. J. Pharm. Sci. 100, 3939-3950. doi: 10.1002/jps.22487

Kamiie, J., Ohtsuki, S., Iwase, R., Ohmine, K., Katsukura, Y., Yanai, K., et al. (2008). Quantitative atlas of membrane transporter proteins: development and application of a highly sensitive simultaneous LC/MS/MS method combined with novel in-silico peptide selection criteria. Pharm. Res. 25, 1469-1483. doi: 10.1007/s11095-008-9532-4

Kauffmann, A., Gentleman, R., and Huber, W. (2009). arrayQualityMetrics-a bioconductor package for quality assessment of microarray data. Bioinformatics 25 , 415-416. doi: 10.1093/bioinformatics/btn647

Krause, G., Winkler, L., Mueller, S. L., Haseloff, R. F., Piontek, J., and Blasig, I. E. (2008). Structure and function of claudins. Biochim. Biophys. Acta. 1778, 631-645. doi: 10.1016/j.bbamem.2007.10.018

Lazarov, O., Robinson, J., Tang, Y. P., Hairston, I. S., Korade-Mirnics, Z., Lee, V. M., et al. (2005). Environmental enrichment reduces Abeta levels and amyloid deposition in transgenic mice. Cell 120, 701-713. doi: 10.1016/j.cell.2005. 01.015

Li, J. Y., Boado, R. J., and Pardridge, W. M. (2001). Blood-brain barrier genomics. J. Cereb. Blood Flow Metab. 21, 61-68. doi: 10.1097/00004647-200101000-00008

Li, K., Dong, D., Yao, L., Dai, D., Gu, X., and Guo, L. (2008). Identification of STC1 as an beta-amyloid activated gene in human brain microvascular endothelial cells using cDNA microarray. Biochem. Biophys. Res. Commun. 376, 399-403. doi: 10.1016/j.bbrc.2008.08.158

Liddelow, S. A., Dziegielewska, K. M., Ek, C. J., Habgood, M. D., Bauer, H., Bauer, H. C., et al. (2013). Mechanisms that determine the internal environment of the developing brain: a transcriptomic, functional and ultrastructural approach. PLoS ONE 8:e65629. doi: 10.1371/journal.pone.0065629

Liddelow, S. A., Temple, S., Mollgard, K., Gehwolf, R., Wagner, A., Bauer, H., et al. (2012). Molecular characterisation of transport mechanisms at the developing mouse blood-CSF interface: a transcriptome approach. PLoS ONE 7:e33554. doi: 10.1371/journal.pone.0033554

Liebner, S., Corada, M., Bangsow, T., Babbage, J., Taddei, A., Czupalla, C. J., et al. (2008). Wnt/beta-catenin signaling controls development of the blood-brain barrier. J. Cell Biol. 183, 409-417. doi: 10.1083/jcb.200806024

Liebner, S., Fischmann, A., Rascher, G., Duffner, F., Grote, E. H., Kalbacher, H., et al. (2000). Claudin-1 and claudin-5 expression and tight junction morphology are altered in blood vessels of human glioblastoma multiforme. Acta Neuropathol. 100, 323-331. doi: 10.1007/s004010000180
Lindahl, P., Johansson, B. R., Leveen, P., and Betsholtz, C. (1997). Pericyte loss and microaneurysm formation in PDGF-B-deficient mice. Science 277, 242-245. doi: 10.1126/science.277.5323.242

Lister, R., O’Malley, R. C., Tonti-Filippini, J., Gregory, B. D., Berry, C. C., Millar, A. H., et al. (2008). Highly integrated single-base resolution maps of the epigenome in Arabidopsis. Cell 133, 523-536. doi: 10.1016/j.cell.2008.03.029

Lopez-Ramirez, M. A., Male, D. K., Wang, C., Sharrack, B., Wu, D., and Romero, I. A. (2013). Cytokine-induced changes in the gene expression profile of a human cerebral microvascular endothelial cell-line, hCMEC/D3. Fluids Barriers CNS 10, 27-8118. doi: 10.1186/2045-8118-10-27

Lyck, R., Ruderisch, N., Moll, A. G., Steiner, O., Cohen, C. D., Engelhardt, B., et al. (2009). Culture-induced changes in blood-brain barrier transcriptome: implications for amino-acid transporters in vivo. J. Cereb. Blood Flow Metab. 29, 1491-1502. doi: 10.1038/jcbfm.2009.72

Lu, L., Yang, P.-Y., Rui, Y.-Ch., Kang, H., Zhang, J., Zhang, J.-P., et al. (2007). Comparative proteome analysis of rat brain and coronary microvascular endothelial cells. Physiol. Res. 56, 159-168.

Lu, Q., Murugesan, N., Macdonald, J. A., Wu, S. L., Pachter, J. S., and Hancock, W. S. (2008). Analysis of mouse brain microvascular endothelium using immuno-laser capture microdissection coupled to a hybrid linear ion trap with Fourier transform-mass spectrometry proteomics platform. Electrophoresis 29, 2689-2695. doi: 10.1002/elps.200700936

Macdonald, J. A., Murugesan, N., and Pachter, J. S. (2008). Validation of immunolaser capture microdissection coupled with quantitative RT-PCR to probe blood-brain barrier gene expression in situ. J. Neurosci. Methods. 174, 219-226. doi: 10.1016/j.jneumeth.2008.07.009

Macdonald, J. A., Murugesan, N., and Pachter, J. S. (2010). Endothelial cell heterogeneity of blood-brain barrier gene expression along the cerebral microvasculature. J. Neurosci. Res. 88, 1457-1474. doi: 10.1002/jnr.22316

Marques, F., Sousa, J. C., Sousa, N., and Palha, J. A. (2013). Blood-brain-barriers in aging and in Alzheimer's disease. Mol. Neurodegener. 8, 38-1326. doi: 10.1186/1750-1326-8-38

Marroni, M., Kight, K. M., Hossain, M., Cucullo, L., Desai, S. Y., and Janigro, D. (2003). Dynamic in vitro model of the blood-brain barrier. Gene profiling using cDNA microarray analysis. Methods Mol. Med. 89, 419-434. doi: 10.1385/1-59259-419-0:419

Masuda, S., Oda, Y., Sasaki, H., Ikenouchi, J., Higashi, T., Akashi, M., et al. (2011). LSR defines cell corners for tricellular tight junction formation in epithelial cells. J. Cell Sci. 124, 548-555. doi: 10.1242/jcs.072058

Mayer, F., Mayer, N., Chinn, L., Pinsonneault, R. L., Kroetz, D., and Bainton, R. J. (2009). Evolutionary conservation of vertebrate blood-brain barrier chemoprotective mechanisms in Drosophila. J. Neurosci. 29, 3538-3550. doi: 10.1523/JNEUROSCI.5564-08.2009

McCandless, E. E., Budde, M., Lees, J. R., Dorsey, D., Lyng, E., and Klein, R. S. (2009). IL-1R signaling within the central nervous system regulates CXCL12 expression at the blood-brain barrier and disease severity during experimental autoimmune encephalomyelitis. J. Immunol. 183, 613-620. doi: 10.4049/jimmunol.0802258

McCandless, E. E., Wang, Q., Woerner, B. M., Harper, J. M., and Klein, R. S. (2006). CXCL12 limits inflammation by localizing mononuclear infiltrates to the perivascular space during experimental autoimmune encephalomyelitis. $J$. Immunol. 177, 8053-8064. doi: 10.4049/jimmunol.177.11.8053

Mojsilovic-Petrovic, J., Nesic, M., Pen, A., Zhang, W., and Stanimirovic, D. (2004). Development of rapid staining protocols for laser-capture microdissection of brain vessels from human and rat coupled to gene expression analyses. $J$. Neurosci. Methods. 133, 39-48. doi: 10.1016/j.jneumeth.2003.09.026

Mortazavi, A., Williams, B. A., McCue, K., Schaeffer, L., and Wold, B. (2008). Mapping and quantifying mammalian transcriptomes by RNA-Seq. Nat. Methods 5, 621-628. doi: 10.1038/nmeth.1226

Murugesan, N., Macdonald, J. A., Lu, Q., Wu, S. L., Hancock, W. S., and Pachter, J. S. (2011). Analysis of mouse brain microvascular endothelium using laser capture microdissection coupled with proteomics. Methods Mol. Biol. 686, 297-311. doi: 10.1007/978-1-60761-938-3-14

Nagalakshmi, U., Wang, Z., Waern, K., Shou, C., Raha, D., Gerstein, M., et al. (2008). The transcriptional landscape of the yeast genome defined by RNA sequencing. Science 320, 1344-1349. doi: 10.1126/science.1158441

Navone, S. E., Marfia, G., Invernici, G., Cristini, S., Nava, S., Balbi, S., et al. (2013). Isolation and expansion of human and mouse brain microvascular endothelial cells. Nat. Protoc. 8, 1680-1693. doi: 10.1038/nprot.2013.107 
Nguyen, L. N., Ma, D., Shui, G., Wong, P., Cazenave-Gassiot, A., Zhang, X., et al. (2014). Mfsd2a is a transporter for the essential omega-3 fatty acid docosahexaenoic acid. Nature 509, 503-506. doi: 10.1038/nature13241

Nielsen, P. A., Andersson, O., Hansen, S. H., Simonsen, K. B., and Andersson, G. (2011). Models for predicting blood-brain barrier permeation. Drug Discov. Today. 16, 472-475. doi: 10.1016/j.drudis.2011.04.004

Nitta, T., Hata, M., Gotoh, S., Seo, Y., Sasaki, H., Hashimoto, N., et al. (2003). Sizeselective loosening of the blood-brain barrier in claudin-5-deficient mice. J. Cell Biol. 161, 653-660.

Obermeier, B., Daneman, R., and Ransohoff, R. M. (2013). Development, maintenance and disruption of the blood-brain barrier. Nat. Med. 19, 1584-1596. doi: 10.1038/nm.3407

Ohtsuki, S., Ikeda, C., Uchida, Y., Sakamoto, Y., Miller, F., Glacial, F., et al. (2013). Quantitative targeted absolute proteomic analysis of transporters, receptors and junction proteins for validation of human cerebral microvascular endothelial cell line hCMEC/D3 as a human blood-brain barrier model. Mol. Pharm. 10, 289-296. doi: 10.1021/mp3004308

Ouyang, S., Hsuchou, H., Kastin, A. J., Wang, Y., Yu, C., and Pan, W. (2014). Diet-induced obesity suppresses expression of many proteins at the blood-brain barrier. J. Cereb. Blood Flow Metab. 34, 43-51. doi: 10.1038/jcbfm.2013.166

Pen, A., Moreno, M. J., Martin, J., and Stanimirovic, D. B. (2007). Molecular markers of extracellular matrix remodeling in glioblastoma vessels: microarray study of laser-captured glioblastoma vessels. Glia 55, 559-572. doi: 10.1002/glia. 20481

Pfeiffer, F., Schafer, J., Lyck, R., Makrides, V., Brunner, S., Schaeren-Wiemers, N., et al. (2011). Claudin-1 induced sealing of blood-brain barrier tight junctions ameliorates chronic experimental autoimmune encephalomyelitis. Acta Neuropathol. 122, 601-614. doi: 10.1007/s00401-011-0883-2

Pottiez, G., Deracinois, B., Duban-Deweer, S., Cecchelli, R., Fenart, L., Karamanos, Y., et al. (2010). A large-scale electrophoresis- and chromatography-based determination of gene expression profiles in bovine brain capillary endothelial cells after the re-induction of blood-brain barrier properties. Proteome Sci. 8:57. doi: 10.1186/1477-5956-8-57

Pottiez, G., Flahaut, C., Cecchelli, R., and Karamanos, Y. (2009). Understanding the blood-brain barrier using gene and protein expression profiling technologies. Brain Res. Rev. 62, 83-98. doi: 10.1016/j.brainresrev.2009.09.004

Qiu, S., Luo, S., Evgrafov, O., Li, R., Schroth, G. P., Levitt, P., et al. (2012). Singleneuron RNA-Seq: technical feasibility and reproducibility. Front. Genet. 3:124. doi: 10.3389/fgene.2012.00124

Reddy, P. H., McWeeney, S., Park, B. S., Manczak, M., Gutala, R. V., Partovi, D., et al. (2004). Gene expression profiles of transcripts in amyloid precursor protein transgenic mice: up-regulation of mitochondrial metabolism and apoptotic genes is an early cellular change in Alzheimer's disease. Hum. Mol. Genet. 13, 1225-1240. doi: 10.1093/hmg/ddh 140

Reese, T. S., and Karnovsky, M. J. (1967). Fine structural localization of a blood-brain barrier to exogenous peroxidase. J. Cell. Biol. 34, 207-217. doi: 10.1083/jcb.34.1.207

Reijerkerk, A., Lopez-Ramirez, M. A., van Het Hof, B., Drexhage, J. A., Kamphuis, W. W., Kooij, G., et al. (2013). MicroRNAs regulate human brain endothelial cell-barrier function in inflammation: implications for multiple sclerosis. J. Neurosci. 33, 6857-6863. doi: 10.1523/JNEUROSCI.3965-12.2013

Risau, W., Hallmann, R., and Albrecht, U. (1986). Differentiation-dependent expression of proteins in brain endothelium during development of the blood-brain barrier. Dev. Biol. 117, 537-545. doi: 10.1016/0012-1606(86) 90321-0

Saunders, N. R., Daneman, R., Dziegielewska, K. M., and Liddelow, S. A. (2013). Transporters of the blood-brain and blood-CSF interfaces in development and in the adult. Mol. Aspects Med. 34, 742-752. doi: 10.1016/j.mam.2012.11.006

Schwabe, T., Bainton, R. J., Fetter, R. D., Heberlein, U., and Gaul, U. (2005). GPCR signaling is required for blood-brain barrier formation in drosophila. Cell 123, 133-144. doi: 10.1016/j.cell.2005.08.037

Searcy, J. L., Le Bihan, T., Salvadores, N., McCulloch, J., and Horsburgh, K. (2014). Impact of age on the cerebrovascular proteomes of wild-type and Tg-SwDI mice. PLoS ONE 9:e89970. doi: 10.1371/journal.pone.0089970

Shawahna, R., Uchida, Y., Decleves, X., Ohtsuki, S., Yousif, S., Dauchy, S., et al. (2011). Transcriptomic and quantitative proteomic analysis of transporters and drug metabolizing enzymes in freshly isolated human brain microvessels. Mol. Pharm. 8, 1332-1341. doi: 10.1021/mp 200129p
Shusta, E. V. (2005). Blood-brain barrier genomics, proteomics, and new transporter discovery. NeuroRx 2, 151-161. doi: 10.1602/neurorx.2.1.151

Shusta, E. V., Boado, R. J., Mathern, G. W., and Pardridge, W. M. (2002). Vascular genomics of the human brain. J. Cereb. Blood Flow Metab. 22, 245-252. doi: 10.1097/00004647-200203000-00001

Siegenthaler, J. A., Sohet, F., and Daneman, R. (2013). 'Sealing off the CNS': cellular and molecular regulation of blood-brain barriergenesis. Curr. Opin. Neurobiol. 23, 1057-1064. doi: 10.1016/j.conb.2013.06.006

Smyth, G. K. (2004). Linear models and empirical bayes methods for assessing differential expression in microarray experiments. Stat. Appl. Genet. Mol. Biol. 3:3. doi: 10.2202/1544-6115.1027

Stenman, J. M., Rajagopal, J., Carroll, T. J., Ishibashi, M., McMahon, J., and McMahon, A. P. (2008). Canonical Wnt signaling regulates organ-specific assembly and differentiation of CNS vasculature. Science 322, 1247-1250. doi: 10.1126/science. 1164594

Stork, T., Engelen, D., Krudewig, A., Silies, M., Bainton, R. J., and Klambt, C. (2008). Organization and function of the blood-brain barrier in Drosophila. J. Neurosci. 28, 587-597. doi: 10.1523/JNEUROSCI.4367-07.2008

Tam, S. J., Richmond, D. L., Kaminker, J. S., Modrusan, Z., Martin-McNulty, B., Cao, T. C., et al. (2012). Death receptors DR6 and TROY regulate brain vascular development. Dev. Cell 22, 403-417. doi: 10.1016/j.devcel.2011.11.018

Tam, S. J., and Watts, R. J. (2010). Connecting vascular and nervous system development: angiogenesis and the blood-brain barrier. Annu. Rev. Neurosci. 33, 379-408. doi: 10.1146/annurev-neuro-060909-152829

Triguero, D., Buciak, J., and Pardridge, W. M. (1990). Capillary depletion method for quantification of blood-brain barrier transport of circulating peptides and plasma proteins. J. Neurochem. 54, 1882-1888. doi: 10.1111/j.14714159.1990.tb04886.x

Uchida, Y., Ohtsuki, S., Katsukura, Y., Ikeda, C., Suzuki, T., Kamiie, J., et al. (2011). Quantitative targeted absolute proteomics of human blood-brain barrier transporters and receptors. J. Neurochem. 117, 333-345. doi: 10.1111/j.14714159.2011.07208.x

Urich, E., Lazic, S. E., Molnos, J., Wells, I., and Freskgard, P. O. (2012). Transcriptional profiling of human brain endothelial cells reveals key properties crucial for predictive in vitro blood-brain barrier models. PLoS ONE 7:e38149. doi: 10.1371/journal.pone.0038149

Vinters, H. V., Reave, S., Costello, P., Girvin, J. P., and Moore, S. A. (1987). Isolation and culture of cells derived from human cerebral microvessels. Cell Tissue Res. 249, 657-667. doi: 10.1007/BF00217338

Wang, S., Qaisar, U., Yin, X., and Grammas, P. (2012a). Gene expression profiling in Alzheimer's disease brain microvessels. J. Alzheimers Dis. 31, 193-205. doi: 10.3233/JAD-2012-120454

Wang, Y., Rattner, A., Zhou, Y., Williams, J., Smallwood, P. M., and Nathans, J. (2012b). Norrin/Frizzled4 signaling in retinal vascular development and blood brain barrier plasticity. Cell 151, 1332-1344. doi: 10.1016/j.cell.2012.10.042

Webster, J. A., Gibbs, J. R., Clarke, J., Ray, M., Zhang, W., Holmans, P., et al. (2009). Genetic control of human brain transcript expression in Alzheimer disease. Am. J. Hum. Genet. 84, 445-458. doi: 10.1016/j.ajhg.2009.03.011

Wilhelm, B. T., Marguerat, S., Watt, S., Schubert, F., Wood, V., Goodhead, I., et al. (2008). Dynamic repertoire of a eukaryotic transcriptome surveyed at singlenucleotide resolution. Nature 453, 1239-1243. doi: 10.1038/nature07002

Wolburg, H., Wolburg-Buchholz, K., Kraus, J., Rascher-Eggstein, G., Liebner, S., Hamm, S., et al. (2003). Localization of claudin-3 in tight junctions of the blood-brain barrier is selectively lost during experimental autoimmune encephalomyelitis and human glioblastoma multiforme. Acta Neuropathol. 105, 586-592. doi: 10.1007/s00401-003-0688-z

Wosik, K., Cayrol, R., Dodelet-Devillers, A., Berthelet, F., Bernard, M., Moumdjian, R., et al. (2007). Angiotensin II controls occludin function and is required for blood brain barrier maintenance: relevance to multiple sclerosis. J. Neurosci. 27, 9032-9042. doi: 10.1523/JNEUROSCI.2088-07.2007

Wu, V. M., and Beitel, G. J. (2004). A junctional problem of apical proportions: epithelial tube-size control by septate junctions in the Drosophila tracheal system. Curr. Opin. Cell Biol. 16, 493-499. doi: 10.1016/j.ceb.2004.07.008

Yousif, S., Marie-Claire, C., Roux, F., Scherrmann, J. M., and Decleves, X. (2007). Expression of drug transporters at the blood-brain barrier using an optimized isolated rat brain microvessel strategy. Brain Res. 1134, 1-11. doi: 10.1016/j.brainres.2006.11.089

Yu, Y. J., and Watts, R. J. (2013). Developing therapeutic antibodies for neurodegenerative disease. Neurotherapeutics 10, 459-472. doi: 10.1007/s13311-013-0187-4 
Zhang, Y., Chen, K., Sloan, S. A., Bennett, M. L., Scholze, A. R., O'Keeffe, S., et al. (2014). An RNA-Sequencing Transcriptome and Splicing Database of Glia, Neurons, and Vascular Cells of the Cerebral Cortex. J. Neurosci. 34, 11929-11947. doi: 10.1523/JNEUROSCI.1860-14.2014

Zhou, L., Sohet, F., and Daneman, R. (2014a). Purification and culture of central nervous system endothelial cells. Cold Spring Harb. Protoc. 2014, 44-46. doi: 10.1101/pdb.top070987

Zhou, Y., Wang, Y., Tischfield, M., Williams, J., Smallwood, P. M., Rattner, A., et al. (2014b). Canonical WNT signaling components in vascular development and barrier formation. J. Clin. Invest. 124, 3825-3846. doi: 10.1172/JCI76431

Conflict of Interest Statement: The authors declare that the research was conducted in the absence of any commercial or financial relationships that could be construed as a potential conflict of interest.
Received: 19 August 2014; paper pending published: 07 September 2014; accepted: 15 October 2014; published online: 06 November 2014.

Citation: Huntley MA, Bien-Ly N, Daneman R and Watts RJ (2014) Dissecting gene expression at the blood-brain barrier. Front. Neurosci. 8:355. doi: 10.3389/fnins. 2014.00355

This article was submitted to Neurogenomics, a section of the journal Frontiers in Neuroscience.

Copyright (C) 2014 Huntley, Bien-Ly, Daneman and Watts. This is an open-access article distributed under the terms of the Creative Commons Attribution License (CC BY). The use, distribution or reproduction in other forums is permitted, provided the original author(s) or licensor are credited and that the original publication in this journal is cited, in accordance with accepted academic practice. No use, distribution or reproduction is permitted which does not comply with these terms. 